Revista Española de

Nutrición Humana y Dietética

Spanish Journal of Human Nutrition and Dietetics
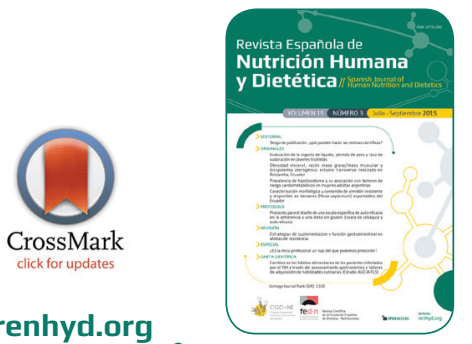

www.renhyd.org

ORIGINAL

\title{
Caracterización morfológica y contenido de almidón resistente y disponible en bananos (Musa sapientum) exportables del Ecuador
}

\author{
Edison Omar Martínez-Mora ${ }^{a, *}$ \\ a Universidad de Machala, El Oro, Ecuador \\ *emartinez@utmachala.edu.ec
}

Recibido el 8 de junio de 2015; aceptado el 14 de julio de 2015.

\section{PALABRAS CLAVE}

Banano;

Almidón resistente;

Almidón digestible.
Caracterización morfológica y contenido de almidón resistente y disponible en bananos (Musa sapientum) exportables del Ecuador

\section{RESUMEN}

Introducción: La investigación tuvo como objetivo fundamental, la caracterización morfológica del almidón nativo de banano (Musa sapientum), contenido en almidón resistente (AR) y disponible (AD), de las variedades de banano de exportación: Cavendish (AC), Filipino (AF), Orito (AO) y Valery (AV).

Material y Métodos: Se determinó tamaño y forma del gránulo de almidón a través de microscopia electrónica de barrido. La cuantificación del AR por medición de su fracción no hidrolizada, luego de un ataque de pepsina, y para la fracción del AD un ataque de amilasa pancreática a la fracción no hidrolizada. Se midió la absorbancia de las dos soluciones de AR y AD a 510nm contra el blanco del reactivo.

Resultados: El tamaño de los gránulos de almidón de: AF, AV y AC fueron en promedio $28 \mu \mathrm{m}$ y para el $A O$, de $35 \mu \mathrm{m}$ aproximadamente. La forma que predominó fue la oval esférica. El contenido de $A R$ y $A D$ estuvo en el rango de 49 a 58,5\% y de 41 a 50\%, respectivamente.

Conclusiones: El almidón resistente, análogo de la fibra y útil en la nutrición humana, se presentó en valores importantes en las muestras de las diferentes variedades de banano exportable del Ecuador, alrededor del 54\%. Según los resultados, el almidón de banano de las variedades estudiadas puede ser incorporado en la elaboración de alimentos que demanden características funcionales, principalmente por su alto contenido en almidón resistente. 


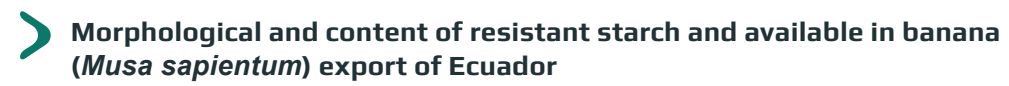

KEYWORDS

Banana;

Resistant starch;

Digestible starch.

\section{CITA}

Martínez-Mora EO. Caracterización morfológica y contenido de almidón resistente y disponible en bananos (Musa sapientum) exportables del Ecuador. Rev Esp Nutr Hum Diet. 2015; 19(3): 153 - 159. D0I: 10.14306/ renhyd.19.3.161

Introduction: The research was fundamental objective, the morphological characterization of native starch banana (Musa sapientum), resistant starch content (AR) and available (AD), the export banana varieties: Cavendish (AC), Filipino (AF), Orito (AO) and Valery (AV).

Material and Methods: Size and shape of the starch granule was determined by scanning electron microscopy. The quantification of AR by measuring its non-hydrolyzed fraction after an attack by pepsin, and for the fraction of $A D$ pancreatic amylase attack on the non-hydrolyzed fraction. The absorbance of the two solutions of $A R$ and $A D$ to $510 \mathrm{~nm}$ against the reagent blank was measured.

Results: The size of the starch granules: $A F, A V$ and $A C$ were on average $28 \mu \mathrm{m}$ and the $A O$, of approximately $35 \mu \mathrm{m}$. The predominant form was the oval ball. The contents of $A R$ and $A D$ ranged from 49 to $58.5 \%$ and from 41 to $50 \%$ respectively.

Conclusions: The resistant starch, fiber and analogue useful in human nutrition, appeared in important values in samples of different varieties of exportable bananas from Ecuador, about $54 \%$. According to the results, the banana starch varieties analized, can be incorporated into food processing demanding functional characteristics, mainly because of its high content of resistant starch.

\section{$r$}

\section{INTRODUCCIÓN}

La necesidad del aprovechamiento integral de los recursos existentes en cada región conduce al estudio exhaustivo de los mismos, como es el caso particular del banano (Musa sapientum). Ecuador es uno de los mayores productores y exportadores de banano a nivel mundial ${ }^{1}$. Trabajos de investigación han reportado que el banano tiene un elevado potencial de utilización, debido a su alto contenido de almidón y aceptables niveles de proteína ${ }^{2,3}$. Estructuralmente, el almidón está constituido de dos polisacáridos, la amilosa y la amilopectina. La amilosa es un polímero lineal de unidades de glucosa, unidas por enlaces a[1-4], en el cual algunos enlaces a[1-6] pueden estar presentes. Esta molécula no es soluble en agua, pero puede formar micelas hidratadas por su capacidad para enlazar moléculas vecinas por puentes de hidrógeno y generar una estructura helicoidal que es capaz de desarrollar un color azul por la formación de un complejo con el yodo ${ }^{4}$; mientras que la amilopectina es un polímero ramificado de unidades de glucosa unidas de 94 a $96 \%$ por enlaces $a[1-4]$ y de 4 a $6 \%$ con uniones $a[1-6]$. Dichas ramificaciones se localizan, aproximadamente, entre 15 a 25 unidades de glucosa. La amilopectina es parcialmente soluble en agua caliente y en presencia de yodo produce un color rojizo violeta 5 .

Desde el aspecto nutricional, el almidón se divide en dos fracciones, almidón digestible (AD) y almidón resistente (AR), este último de mayor interés por ser considerado como análogo de fibra ${ }^{6}$. EI AR se puede definir como la cantidad total de almidón y de sus productos de degradación, resistentes a la digestión en el intestino delgado de individuos sanos ${ }^{7}$. 
El presente trabajo tuvo como objetivo fundamental determinar la morfología del gránulo de almidón nativo de banano (Musa sapientum), fracción resistente y digestible, y su potencial incorporación en la elaboración de alimentos que demanden de características funcionales. Las variedades de banano de exportación estudiadas fueron: Cavendish (AC), Filipino (AF), Orito (AO) y Valery (AV).

\section{MATERIAL Y MÉTODOS}

La determinación de las características morfológicas del gránulo de almidón, se realizó en el laboratorio de Nutrición de la Universidad Autónoma del Estado de Hidalgo, México, en el período enero-febrero 2015. El contenido en AR y AD del almidón nativo de banano (Musa sapientum) exportable del Ecuador se cuantificó en los laboratorios de la Unidad de Ciencias Químicas y la Salud, de la Universidad Técnica de Machala, Ecuador, en el período febrero-abril 2015.

\section{Tamaño y forma de los gránulos de almidón}

Para evaluar la forma y tamaño del gránulo de almidón nativo de banano (Musa sapientum) inmaduro se utilizó un microscopio electrónico de barrido de alto vacío, con alcance de 300000 magnificaciones, resolución de $30 \mathrm{Kv}$, equipo con un detector de energía dispersiva de rayos $X$.

\section{Determinación de AR y AD}

Descripción del método: Las muestras se incuban en baño de agua sacudiendo con a-amilasa pancreática y amiloglucosidasa (AMG) por 16 horas a 37ํㄷ; durante el proceso el almidón no resistente es solubilizado e hidrolizado a D-glucosa por la acción combinada de las dos enzimas. La reacción es terminada por la adición de un volumen igual de etanol o alcohol industrial (IMS, etanol desnaturalizado) y el AR se recupera como en el residido de centrifugación. Después esto se lava dos veces por suspensión acuosa IMS o etanol (50\% v/v), seguido de centrifugación. Se extrae líquido libre por decantación. AR en el residuo precipitado se disuelven en $2 \mathrm{M} \mathrm{KOH}$ agitando vigorosamente en un baño de agua helada sobre un agitador magnético.

Esta solución se neutraliza con tampón de acetato y el almidón se hidroliza cuantitativamente a glucosa con AMG. Dglucosa se mide con el reactivo de glucosa oxidasa/peroxidasa (GOPOD), y ésta es una medida de contenido de AR en la muestra. El AD se determina por juntar el sobrenadante original y los lavados, ajustar el volumen a $100 \mathrm{~mL}$ y medir el contenido de D-glucosa con GOPOD. La cuantificación del almidón resistente se hizo por medición de la fracción no hidrolizada, con un ataque de pepsina, simulando condiciones estomacales y luego sometiendo esta fracción al ataque de la amilasa pancreática ${ }^{8}$. El almidón digestible a través de un ataque amilolítico ${ }^{9}$ y almidón total como la suma del almidón digestible y resistente.

Aplicabilidad y precisión: El método es aplicable a muestras que contengan más de $2 \% \mathrm{~m} / \mathrm{m}$ de AR. Con dichas muestras, se obtienen rutinariamente los errores estándar de $\pm 5 \%$. Se obtienen mayores errores para muestras con $A R$ contenidos $<2 \% \mathrm{~m} / \mathrm{m}$.

Obtención de muestra de almidón: El almidón se obtuvo del banano inmaduro (Musa sapientum) de las variedades Filipino, Valery, Cavendish y Orito, los cuales fueron proporcionados por el programa bananero de la Universidad Técnica de Machala, El Oro (Ecuador). Los cultivares fueron cosechados en temporada seca, a $4 \mathrm{~m}$ sobre el nivel del mar, una humedad relativa de $75 \%$ y temperatura promedio de $28^{\circ} \mathrm{C}$. El método de obtención de almidón ${ }^{3}$ consistió en pesar lotes entre 100 y $150 \mathrm{~kg}$ del fruto, se separó la cáscara y se cortaron rodajas de $1 \mathrm{~cm}$. Después, el fruto se colocó dentro de un contenedor con ácido cítrico al 0,3\%. Se realizó una molienda en húmedo, se cribó sucesivamente en mallas de: 0,841; 0,$420 ; 0,149$ y 0,074mm. En cada malla, el residuo se lavó hasta que el líquido de salida no tuviera residuo aparente de almidón. La suspensión obtenida se separó por precipitación del almidón; luego de decantado se secó por medio de una estufa entre 48 y $50^{\circ} \mathrm{C}$ durante $48 \mathrm{~h}$ y finalmente se pulverizó el almidón en un molino de martillo. El contenido de humedad del almidón se determinó por AOAC, método 925.10 10 .

Hidrólisis y solubilización del AD: Consistió en: i) pesar exactamente una muestra de $105 \mathrm{mg}$ de almidón de banano directamente en un tubo de tapón de rosca (tubo de cultivo Corning; $16 \times 125 \mathrm{~mm})$; ii) añadir 4,0mL de a-amilasa pancreática $(10 \mathrm{mg} / \mathrm{mL})$ que contiene AMG $(3 \mathrm{U} / \mathrm{mL})$; iii) tapar los tubos firmemente, mezclar en un vórtex y adjuntarlos horizontalmente en un baño de agua con agitación y alinear en la dirección del movimiento; iv) incubar los tubos a $37^{\circ} \mathrm{C}$ con agitación continua (200 golpes/min), exactamente durante $16 \mathrm{~h}$; v) retirar los tubos del baño y quitar el exceso de agua superficial con toalla de papel; vi) retirar los tapones de tubo y tratar los contenidos con 4,0mL de etanol (99\%v/v) o IMS $(99 \% \mathrm{v} / \mathrm{v})$ con agitación vigorosa en un vórtex; vii) centrifugar los tubos a 3000rpm aproximadamente, durante $10 \mathrm{~min}$ (sin tapa); viii) decantar cuidadosamente el sobrenadante y resuspender el pellet en $2 \mathrm{~mL}$ de etanol al $50 \%$ o el $50 \%$ IMS con agitación vigorosa en un vórtex; ix) añadir otros $6 \mathrm{~mL}$ de $50 \%$ IMS, mezclar los tubos y centrifugar nuevamente a 3000rpm durante $10 \mathrm{~min}$; $\mathrm{x}$ ) decantar el sobrenadante $\mathrm{y}$ repetir una vez más este paso suspensión y centrifugación; y xi) decantar el sobrenadante e invertir los tubos sobre un papel absorbente para drenar el exceso de líquido. 
Medición del AR: Consistió en añadir un agitador magnético y $2 \mathrm{~mL}$ de $2 \mathrm{M} \mathrm{KOH}$ a cada tubo con los resuspendidos pellets (para disolver el AR removiendo durante aproximadamente 20min en un baño de hielo/agua mediante el agitador magnético). Se añadieron $8 \mathrm{~mL}$ de tampón de acetato de sodio de 1,2M $(\mathrm{pH} 3,8)$ a cada tubo con el agitador magnético. Inmediatamente se añadió 0,1mL de AMG (solución 1; $3300 \mathrm{U} / \mathrm{mL}$ ), mezclando bien y colocando los tubos en un baño de agua a $50^{\circ} \mathrm{C}$. Seguidamente se incubaron los tubos, durante $30 \mathrm{~min}$, con la mezcla intermitente en un vórtex. Se transfirió el contenido del tubo cuantitativamente a un matraz aforado de $100 \mathrm{~mL}$. A continuación, se ajustó a $100 \mathrm{~mL}$ con agua destilada y se mezcló bien para pasar a centrifugar una parte alícuota de la solución a 3000rpm durante $10 \mathrm{~min}$. Inmediatamente se transfirieron alícuotas de $0,1 \mathrm{~mL}$ (por duplicado) del diluido en tubos de ensayo de vidrio $(16 \times 100 \mathrm{~mm})$; se añaden $3,0 \mathrm{~mL}$ de reactivo de GOPOD y se incuba a $50^{\circ} \mathrm{C}$ durante $20 \mathrm{~min}$. Por último se mide la absorbancia de la solución a $510 \mathrm{~nm}$ contra el blanco del reactivo.

Medición del AD: Se debe combinar las soluciones sobrenadantes obtenidas por centrifugación de la incubación inicial con los sobrenadantes obtenidos de los siguientes 2 lavados etanol de 50\% (hidrólisis del AD). Se ajusta el volumen con tampón de acetato de sodio $100 \mathrm{mM}(\mathrm{pH} 4,5)$ en un matraz aforado de $100 \mathrm{~mL}$. Se mezcla bien y se incuban alícuotas de $0,1 \mathrm{~mL}$ de esta solución (por duplicado) con $10 \mu \mathrm{L}$ de la solución diluida de AMG $(300 \mathrm{U} / \mathrm{mL})$ en $100 \mathrm{mM}$ sodio maleato de tampón (pH 6,0 durante $20 \mathrm{~min}$ a $50^{\circ} \mathrm{C}$.). Se añaden $3,0 \mathrm{~mL}$ de reactivo de GOPOD y se incuban los tubos por un adicional de $20 \mathrm{~min}$ a $50^{\circ} \mathrm{C}$. Por último se mide la absorbancia a $510 \mathrm{~nm}$ contra un blanco del reactivo y se calcula el contenido de almidón no resistente. El contenido de almidón total es la suma de almidón resistente y el almidón digestible.

Los resultados fueron procesados utilizando el paquete estadístico SPSS versión 19.0. Se calculó el análisis de varianza y prueba post hoc por el método de Tukey. Todas las corridas experimentales fueron realizadas por triplicado, señalando los valores de significancia $p \leq 0,05(X / D S, n=3)$.

\section{RESUltados}

Los gránulos de almidón de las diferentes variedades de banano presentaron una superficie lisa, de forma ovoide y en algunos casos redondos (Figura 1). El tamaño de los almidones de AF, AV y AC fueron en promedio $28 \mu \mathrm{m}$ y para el $\mathrm{AO}$, de $35 \mu \mathrm{m}$, aproximadamente (Tabla 1 ).

Figura 1. Microfotografía de los gránulos de almidón de banano inmaduro (Musa sapientum) de las cuatro variedades seleccionadas.

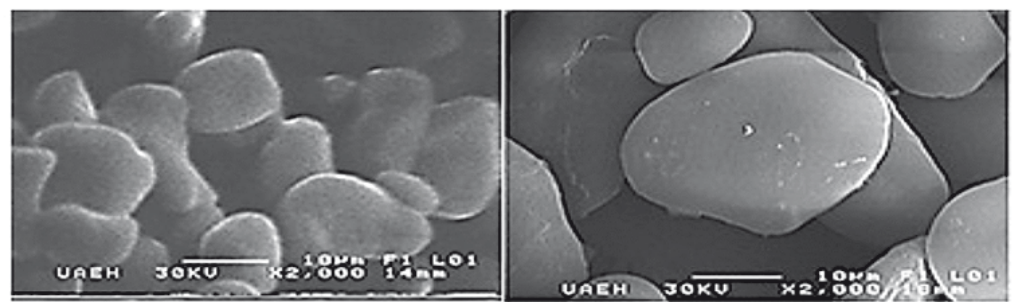

Cavendish

Filipino

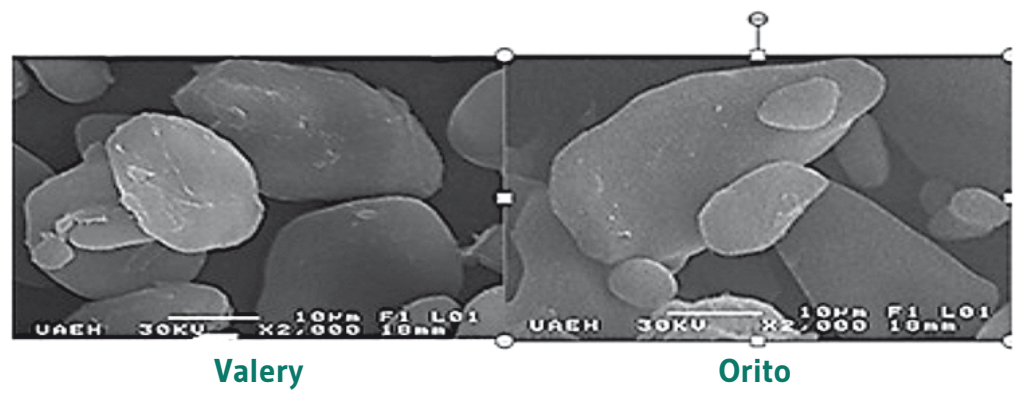


Tabla 1. Tamaño promedio y forma de los gránulos de almidón de banano.

\begin{tabular}{c|c:c} 
Muestra & Tamaño $(\mu \mathrm{m})^{*}$ & Forma \\
\hline AF & $\begin{array}{c}25,1^{\mathrm{a}} \\
(1,8)\end{array}$ & Oval - esférico \\
\hline AV & $\begin{array}{c}30,2^{\mathrm{a}} \\
(2,4)\end{array}$ & Oval - esférico \\
\hline AC & $\begin{array}{c}25,1^{\mathrm{a}} \\
(0,7)\end{array}$ & Oval - esférico \\
\hline AO & $\begin{array}{c}35,1^{\mathrm{a}} \\
(3,0)\end{array}$ & Oval - esférico \\
\hline
\end{tabular}

* $\mu$ m micrómetros x 2000 aproximaciones.

AF: almidón de banano variedad Filipino; AC: almidón de banano variedad Cavendish; AO: almidón de banano variedad Orito; AV: almidón de banano variedad Valery. Los valores informados corresponden a la media y la desviación estándar ( $n=3)$.

Valores medios en la misma columna con letra distinta son significativamente diferentes $(p<0,05)$.

La Tabla 2 muestra que en todos los almidones nativos estudiados su contenido en almidón resistente y digestible estuvo en los rangos de 49,33 a $58,57 \%$ y de 41 a $50 \%$, respectivamente.

Tabla 2. Contenido de almidón resistente y digestible.

\begin{tabular}{|c|c|c|}
\hline Variedad & Almidón resistente & Almidón digestible \\
\hline AF & $\begin{array}{c}56,84^{a} \\
(1,78)\end{array}$ & $\begin{array}{c}43,16^{b} \\
(3,13)\end{array}$ \\
\hline AV & $\begin{array}{l}58,57^{a} \\
(3,94)\end{array}$ & $\begin{array}{l}41,43^{b} \\
(3,56)\end{array}$ \\
\hline AC & $\begin{array}{c}49,33^{b} \\
(2,07)\end{array}$ & $\begin{array}{c}50,67^{\mathrm{a}} \\
(4,34)\end{array}$ \\
\hline AO & $\begin{array}{l}52,81^{b} \\
(2,66)\end{array}$ & $\begin{array}{c}47,19^{a} \\
(3,31)\end{array}$ \\
\hline
\end{tabular}

AF: almidón de banano variedad Filipino; AC: almidón de banano variedad Cavendish; AO: almidón de banano variedad Orito; AV: almidón de banano variedad Valery. Los valores informados corresponden a la media y la desviación estándar $(n=3)$. Valores medios en la misma columna con letra distinta son significativamente diferentes $(p<0,05)$. 


\section{Discusión y conclusiones}

Las características morfológicas de los almidones de diferentes orígenes varían con el genotipo y las prácticas de cultivo. La variación en el tamaño y la forma de los gránulos es atribuida al origen biológico ${ }^{11}$ y es común su empleo para su identificación.

Como se aprecia en la Figura 1, la forma de los gránulos de almidón en todos los casos fue similar, con predominio de la forma ovalada y superficie alisada. No obstante, existieron ciertas diferencias en cuanto a las dimensiones: la variedad Cavendish presentó gránulos homogéneos de menor tamaño; de manera similar ocurrió con la variedad Filipino; mientras que las variedades Orito y Valery presentaron gránulos de mayor tamaño, sin embargo existió presencia de gránulos pequeños, mostrando mayor variabilidad. Al comparar con otras fuentes de almidón, los tamaños de estas variedades se encuentran en el mismo intervalo que el almidón de trigo ${ }^{12}$, de 22 a $55 \mu \mathrm{m}$. Esta condición favorecerá la homogeneidad granular de las harinas compuestas, que con estos almidones se pretenda elaborar alimentos farináceos.

Al iniciar el proceso de secado del almidón, es frecuente que exista un exceso de agua que puede contribuir a la gelatinización irreversible, contribuyendo al aumento de almidones resistentes. Por esa razón, en la presente investigación se tuvo precaución de mantener temperaturas inferiores a los $60^{\circ} \mathrm{C}$. Los gránulos de almidón nativo son capaces de absorber agua hasta el $30 \%$ de su masa cuando se remojan ${ }^{13}$, debido a la existencia de casi un $50 \%$ de almidón digestible en todos los almidones de frutas; ello indica la presencia de gránulos capaces de absorber agua, sin llegar a gelatinizar e incrementar así su susceptibilidad al ataque enzimático. La muestra de almidón nativo no se deberá someter a ningún proceso que modifique su estabilidad ${ }^{14}$. Bajo esta premisa, los resultados son más reales porque la acción enzimática (amilolisis) ocurre en condiciones a las cuales el almidón no se ha gelatinizado por el propio diseño del método analítico ${ }^{9}$. Los valores de AR y AD concuerdan ${ }^{15}$ y difieren con otros autores ${ }^{16}$. La diferencia, a favor del presente trabajo, se podría deber a que las otras investigaciones no detallan la temporada de cosecha, época seca o lluviosa, terraza climática del cultivo o variedad de la Musaceae, entre otros factores. En nuestro caso se cosechó en temporada seca, a $4 \mathrm{~m}$ sobre el nivel del mar, con una humedad relativa de $75 \%$, temperatura promedio de $28^{\circ} \mathrm{C}$ y cultivares de Musa sapientum.

Se puede concluir que los gránulos de almidón de banano inmaduro exportable del Ecuador, de las variedades Filipino, Valery, Cavendish y Orito, presentaron una misma forma oval esférica, con tamaños que van desde las 25 a las
35 micras. El almidón resistente, análogo de la fibra y útil en la nutrición humana, presenta valores importantes en la muestras de las diferentes variedades de banano, alrededor de $54 \%$. Según los resultados obtenidos, el almidón de banano de las variedades estudiadas puede ser incorporado en la elaboración de alimentos, como matriz o insumo, que demanden de características funcionales.

\section{AGRADECIMIENTOS}

Al Departamento de Nutrición de la Universidad Autónoma del Estado de Hidalgo, México; y a la Unidad Académica de Ciencias Químicas y la Salud de la Universidad de Machala, Ecuador.

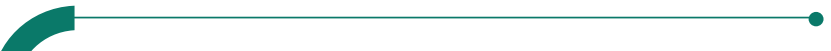 CONFLICTO DE INTERESES}

Los autores manifiestan que no existen conflictos de intereses al redactar el manuscrito.

\section{BIBLIOGRAFÍA}

1. Banco Central del Ecuador (BCE). Estadísticas de comercio exterior. (Citado 5 abril 2015). Disponible en: http://www. portal.bce.fin.ec/vto_bueno/comercioexterior.jsp.

2. Zamudio P, Vargas A, Gutiérrez F, Bello L. Caracterización fisicoquímica de almidones doblemente modificados de plátano. Agrociencia. 2010; 44(3): 287.

3. Guerra D, Bello A, González A, Solorza J, Arámbula G. Efecto del tiempo de reacción de la acetilación de almidón de plátano. Revista Mexicana de Ingeniería Química. 2008; (7): 284-5.

4. Knutzon CA, Grove M]. Rapid method for estimation of amylose in maize starches. Cereal Chem. 1994; 71(5); 469-70.

5. Guan, J, Hanna MA. Extruding foams from corn starch acetate and native corn starch. Biomacromolecules. 2004; 5(6); 232939.

6. Delcour J, Eerlinger R. Analytical implications of the classification of resistant starch as dietary fiber. Cereal Foods World. 1996; 41: 85-6.

7. Escarpa A, González M, Mañas E, García L, Saura F. Food Sci Technol Int. 1997; 3: 149-60.

8. Morrison W, Laignelet B. An improved colorimetric procedure for determining apparent and total amylose in cereal and other starches. Journal of Cereal Science. 1983; 1: 19-35.

9. Goñi I, Garcia L, Muñoz E, Saura F. Analysis of resistant starch: a method for foods and food products. Food Chem. 1997; 56: 445-9. 
10. AOAC. American Organization of Analytical Chemists. Official Methods of Analysis. 1990; 777.

11. Svegmark K, Hermansson A. Microstructure and rheological properties of composites of potato starch granules and amylose: a comparison of observed and predicted structure. Food Structure. 1993; 12(2): 181-93.

12. Kett A. Development of food ingredients for modulation of glycemia. PhD Thesis, University College Cork. 2013; 11-12.

13. Goñi I, García-Diz L, Mañas E, Saura-Calixto F. Analysis of resistant starch: a method for foods and food products. Food Chem. 1996; 56(4); 445-9.
14. Abdoulaye S, Issoufou A, Wei-Rong Y. Application of resistant starch in bread: processing, proximate composition and sensory quality of functional bread products from wheat flour and African locust bean (Parkia biglobosa) flour. Agricultural Sciences. 2013; 4(5B): 122-9.

15. Ovando M, Sáyago S, Agama-Acevedo E, Goñi I, Bello-Pérez $\mathrm{L}$. Unripe banana flour as an ingredient to increase the undigestible carbohydrates of pasta. Food Chem. 2009; 113: 121-6.

16. McCleary B, Monaghan D. Measurement of Resistant Starch. J AOAC Int. 2002; 85(3): 665-75. 